\title{
The Effects of Aroma Hand Massage on Fatigue and Sleeping among Hospice Patients
}

\author{
Heeok Park ${ }^{1}$, Youngmi Chun ${ }^{2}$, Sooyoung Kwak ${ }^{3}$ \\ ${ }^{1}$ College of Nursing, Keimyung University, Daegu, South Korea \\ ${ }^{2}$ College of Nursing, Taegu Science University, Daegu, South Korea \\ ${ }^{3}$ Department of Nursing, Keimyung College University, Daegu, South Korea \\ Email: jerry1032@hanmail.net, hopark@kmu.ac.kr, sykwak@kmcu.ac.kr
}

Received 28 May 2016; accepted 5 July 2016; published 8 July 2016

Copyright (C) 2016 by authors and Scientific Research Publishing Inc.

This work is licensed under the Creative Commons Attribution International License (CC BY). http://creativecommons.org/licenses/by/4.0/

(C) (i) Open Access

\section{Abstract}

Purpose: The purpose of this study was the comparative effects on fatigue and sleep of aroma hand massage vs. hand massage among hospice patients in a hospital. Methods: The design of this study was a nonequivalent comparison group pretest-posttest design. This study was performed from May to December 2012 in a hospice ward. A total of 30 hospice patients in a hospice ward participated in the study (17 in an aroma massage group and 13 in a massage group). The Piper Fatigue Scale was used to measure the fatigue level. The quantity of sleep was measured using sleep hours and the quality of sleep using the Verran \& Snyder-Halpern sleep scale (1987). The aroma massage group used 1:1 lavender and bergamot diluted to $1 \%$ with $100 \mathrm{ml}$ jojoba carrier oil. The massage group used carrier oil without an essential oil. Each treatment was performed for 10 minutes prior to the subject's sleeping time, once a day and for 5 days. Data were analyzed using t-test, $\mathrm{x}^{2}$-test, Fisher's exact test and the repeated measures ANOVA with the SPSS program. Results: The increase in the fatigue and decrease in the sleep quantity were lower in the aroma hand massage compared to the only hand massage but they were not statistically significant. Conclusion: The quality of sleeping improved in the aroma hand massage group compared to the control group even though it was not significant. For the further studies, assessing and respecting the patient's aroma preference were important considerations when providing aromatherapy and the appropriation of using $1 \%$ essential oil to dilute needs to be tested for the hospice patients in the further studies

\section{Keywords}

Hospices, Aromatherapy, Fatigue, Sleep 


\section{Introduction}

Hospice care provides supportive care to terminally ill clients and the focus of care is on giving comfort to the patient and improving the quality of life rather than cure [1]. The goal of hospice care is to enable patients to be comfortable and pain free so that they live each day as fully as possible [1]. With the increase in the number of older adults and cancer patients, the number of hospice clients had increased to 71,579 in South Korea in 2011 which was a $21.4 \%$ increase from 2000 [2]. In addition, the number of hospice clients in hospice wards has also increased because hospice care including end of life care in the past is given by families or relatives in the clients' home in South Korea, but is being largely provided in hospice wards in hospitals [3].

Hospice clients experience diverse health problems including physical and emotional problems such as pain, anger, anxiety, helplessness and depression, and they also suffer from the monetary burden of medical expenses [3]. For these reasons, hospice clients show physical and emotional symptoms and the symptoms are usually related to severe fatigue and a low quality of sleeping [4]. Fatigue is defined as a subjective state in which one feels tired or exhausted and is related to disturbances, depressive symptoms, paralyzed status and restlessness [5]. Especially, fatigue in cancer patients is related to weight change, ADL status, pain, immobility, sleeping [6] [7].

Sleeping is a necessary factor for normal activity and is related to well-being and the quality of life. Sleeping is related to the low education level, poor economic status, no religion, no spouse, no exercise, low perceived health condition, bad perceived family relationship [8] [9]. An appropriate level of sleeping improves tissue restoration, functions of immune system, emotional functions and the quality of life [10]. However, sleeping disturbances are general symptoms occurring in hospice patients and they produce negative effects including physical and emotional problems. Sleeping disorder is a risk factor for fatigue, anxiety and depression and eventually causes weakness, isolation and sense of loss [10].

Because fatigue and sleeping disturbances are serious problems for hospice clients, many non-pharmacological interventions are used to improve the problems, including music intervention, aromatherapy, horticulture therapy and image therapy [11]-[13]. Of these interventions, aromatherapy is defined as the "use of essential oils for therapeutic purposes that encompass mind, body, and spirit" [14] and it is the therapeutic use of essential oils derived from plants and these oils can be absorbed into the body via the skin or the olfactory system [15]. Each essential oil acts as olfactory stimulants via the olfactory bulb to the limbic system of the brain which includes the amygdala and the hippocampus [16]. The amygdala governs emotional responses and the hippocampus involves in the retrieval of explicit memories. Aroma therapy is an appropriate non-pharmacological intervention for hospice clients because it is non-invasive and easy to provide.

The previous studies have reported the positive effects of aromatherapy in alleviating physical problems such as pain and in the improvement of daily activities, but additionally, amelioration of emotional problems such as depression and anxiety have been described [17] [18] as well. However, studies to investigate the effect of aroma therapy focused on elderly inpatients, hemodialysis patients or painful patients in Korea [19]-[21]. In addition, these studies were limited to other health problems more than fatigue and sleeping [11] [22].

Because fatigue and sleeping problems are significantly related with well-being and the quality of life in hospice clients, it is very important to decrease clients' fatigue levels and improve their sleep. In addition, many studies related to aromatherapy offered interventions only once or measured the immediate effects [22] [23]. In addition, Halcon and Buckle (2006) [16] reported the essential oils are absorbed through the skin by diffusion and massage also can facilitate absorption of essential oils so that aromatherapy using massage can enhance the effects of interventions [16]. Therefore, there is a need to test the repeated use of an aromatherapy with massage and to test the long term effects on fatigue and sleeping. The findings of this study would therefore provide meaningful data for the provision of aromatherapy to hospice clients.

The present study compared the effects of aroma hand massage with only hand massage on fatigue and sleeping for hospice patients in a hospital, with the aim of suggesting practical nursing interventions to improve fatigue and sleep: 1) Subjects participating in aroma hand massage group(experimental group) will experience a lower level of fatigue, as compared to the hand massage group(comparison group) and 2) Subjects participating in the experimental group will experience better sleep compared to the comparison group.

\section{Methods}

\subsection{Research Design}

This study was of nonequivalent pretest-posttest design to compare the effects of aroma massage group with 
only massage group on fatigue and sleeping for hospice patients in a hospice ward.

\subsection{Sample and Settings}

A total of 30 subjects (17 in the experimental group and 13 in the comparison group) had participated in this study. Inclusion criteria of the study were 1) diagnosed as a hospice patient; 2) not having any kind of allergy to aroma oils; 3 ) not having lesions on both hands; 4) being able to understand the questionnaires and communicate verbally; 5) consent given to participate in the study; 6) having families who agreed to participate in the study.

Originally, the first 18 subjects were assigned into the experimental group and the next 18 to the control group accordingly but 2 subjects in the control group expired right after the assignment so a total of 34 subjects participated in the study (18 in the experimental group and 16 in comparison group). During the research period, 1 client in the experimental group and 3 in the comparison group dropped from the study for reasons such as death (2), mental deterioration (1) and reluctance to smell the aroma odor (1). In the end, there were 17 clients in the experimental group and 13 clients in the comparison group who completed the study. Based on the G*Power 3 Program analysis [24] for repeated measures ANOVA (with medium effect 0.25; power 0.75; and alpha value 0.05), a minimum sample size for each group was set as 15 and the number of subjects in this study satisfied the minimum sample size.

\subsection{Measurements}

\subsubsection{Fatigue}

The Piper Fatigue Scale developed by Piper et al. (1998) [25] and translated by Sohn (2002) [26] was used to measure the level of fatigue. The questionnaire includes a total of 22 questions in 4 areas (behavioral/severity area: 6 questions; affective meaning area: 5 questions; sensory area: 5 questions; cognitive/mood area: 6 questions) [25]. The Visual Analogue Scale (VAS) from 0 to 10 points was used for each question. A higher score in the questionnaire meant a higher level of fatigue. The Cronbach's alpha value of the questionnaire was initially 0.97 and the value in this study was set at 0.87 .

\subsubsection{Sleep}

1) Quantity of sleep: quantity of sleep means the number of hours slept during the night from the time of going to bed to the time the subject wakes up.

2) Quality of sleep: the sleep scale was developed by Verran \& Snyder-Halpern (1987) [27] [28] and translated by Kang\& Kim (1994) [29]. The questionnaire includes a total of 8 questions with the Visual Analogue Scale (VAS) from 0 to 10 points. Ahigher score in the questionnaire means a higher level in the quality of sleep. The Cronbach's alpha value of the questionnaire was initially 0.82, 0.80 in Kang\& Kim's study (1994) [29] and 0.76 in this study.

\subsection{Data Collection}

The study was approved by the D Hospital IRB committee members (IRB NO: 12 - 63) in D city, and data collection was started after the IRB approval. This study was conducted from May to December 2012 in a hospice ward. The principal investigator (PI) contacted the director of nursing, head nurses and nurses in the D-Hospital of Korea that was less than 1 hour's drive from the PI's office and explained the purpose, specific contents and procedure of the study. When they agreed to introduce the study to the hospice clients and their families, the PI visited the hospice ward to explain the study to the hospice clients and their families. When the hospice clients showed the interests to participate in this study during the hospitalization, the PI explained about the purpose of this study at clients' rooms. The PI obtained a formal consent from each of the subjects and their families when they agreed. The data collection was started when after consents were obtained. All patients and their families were informed that they were allowed to withdraw their consent at any time point if they did not want to continue the participation. The personal information of the participant was confidentially kept in the PI's office room.

Three Research Assistants (RAs) provided aroma hand massage for the experimental group and hand massage for the comparison group. The 3 RAs were nurses with working experiences at a hospice ward for $>5$ years and who had been trained by international aroma therapists. Before the data collection started, they were trained to provide the massage with same contents and procedures. The RAs were assigned to provide the aroma hand 
massage for the experimental group and the hand massage for the comparison group in a row. For example, the RA 1 was assigned to the experimental group, the RA 2 was assigned to the comparison group, the RA 3 was assigned to the experimental group and the RA 1 was assigned to the comparison group.

The subjects' characteristics were recorded for the pre-test. The Piper Fatigue Scale [25] [26] and a sleep questionnaire using Verran \& Snyder-Halpern (VSH) [27] [29] were initially measured for both groups. For the post-test, the fatigue levels were measured when the last and fifth massage had been completed and the sleep level was measured 5 times when every single massage was conducted for the both groups. Specific explanations regarding the aroma massage in the experimental group and the only massage in the comparison group were as follows.

\subsection{Interventions}

- Aroma hand massage (experimental group)

The way of doing the aroma massage in this study was originally developed by the Korea Aromatherapy Association (1997) [30] and the aroma massage was provided using blended oil (a mixture of lavender and bergamot essential oil in a 1:1ratio that was diluted to $1 \%$ with $100 \mathrm{ml}$ jojoba carrier oil). The aroma hand massage was performed for 10 minutes ( 5 minutes for each hand) right before the sleeping time for 5 consecutive days (a total of 5 times for each subject; once a day). Lavender and bergamot essential oils were used in this study because essential oils were found to make clients relaxed in previous studies [15] [21].

The oil was blended to $1 \%$ in this study because essential oil diluted to $1 \%$ was used in the previous studies for cancer patients [31] [32]. The aroma hand massage was performed at $9 \sim 10 \mathrm{pm}$ because the hospice clients in this study went to sleep at around $10 \mathrm{pm}$. The hand aroma massage was applied for a period of 5 minutes for each hand and the duration of massage was chosen based on findings of previous studies that nursing interventions longer than 10 minutes increased the fatigue in hospice clients.

The aroma hand massage was offered for a total of 5 times for 5 consecutive days because hospice clients usually stay in a hospice ward for less than 7 days in South Korea and because it was difficult to communicate with the subjects as they approached the end of their life, even though a hand aroma massage had been provided for many days for other kinds of patients.

The specific procedure of aroma hand massage provided in this study was as follows:

1) Drop 3 - $5 \mathrm{~mL}$ of oil into both hands, rub the hands lightly and apply the oil to the clients' hands.

2) Make a circle by pressing with your two thumbs on a client's wrist.

3) Gently press the client's palm with your two thumbs.

4) Make a circle by pressing with your fist on the client's palm.

5) Help the client's arm stretch to each side with your hands.

6) Tendon work: pressing and pulling the middle part of the client's metacarpal with your fingers.

7) Press each finger of the client with your thumb and direction finger.

8) Put your fingers between the client's joints and pull your fingers back by pressing.

9) Wrap the client's hands up with both your palms and pull the client's hands gently.

\subsection{Hand Massage (Comparison Group)}

Only hand massage without any type of aroma was offered in the comparison group and provided with only jojoba carrier oil(without essential oils)according to the massage technique of the Korea Aromatherapy Association (1997) [30]. The hand massage was given at $9 \sim 10 \mathrm{pm}$ for 10 minutes ( 5 minutes for each hand) a total of 5 times over 5 days in the same way.

\subsection{Data Analysis}

Data analysis was conducted using the SPSS/WIN version 18.0 program (SPSS, Inc., an IBM Company, Chicago, llinois, USA). Descriptive statistics were used to describe the subject's characteristics. T-test, $\chi^{2}$-test, Fisher's exact test, and the repeated measures ANOVA were used to test the research questions.

\section{Results}

Subject's characteristics were presented in Table 1. Over half of participants in the experimental group were 
male 10 (59\%), 50 - 69 years old 9 (53\%), had a religion 9 (53\%), were married 12 (71\%) and were less than high school graduates 12 (70\%). Over half of participants in the comparison group were female 7 (54\%), less than 69 years old 9 (69\%), had a religion 10 (77\%), were married 8 (62\%) and were less than high school graduates 8 (62\%). Most participants in both groups had been diagnosed with cancer 11 (65\%) in the experimental group and 7 (54\%) in the control group, had caregivers (9 (53\%) and $10(77 \%))$, were on their first admission at this time (13 (76\%) and 9 (69\%)) and admitted to pain control (10 (59\%) and 7 (54\%)). There were no differences in subjects' characteristics, fatigue and sleep levels between the groups at pre testing.

The study findings on fatigue were presented in Table 2 . The fatigue level in the experimental group increased by 0.06 (from 6.03 to 6.09) and the level in the comparison group increased by 0.16 (from 6.15 to 6.31 ) indicating no significant difference in fatigue levels between the experimental and comparison group. The changes in the quantity of sleep in both groups were presented in Table 3 . The quantity of sleep in the experi-

Table 1. Subject's characteristics and homogeneity test $(\mathrm{N}=30)$.

\begin{tabular}{|c|c|c|c|c|c|}
\hline \multirow{2}{*}{ Characteristics } & \multirow{2}{*}{ Category } & Exp. $(n=17)$ & Con. (n = 13) & \multirow{2}{*}{$t / x^{2}$} & \multirow{2}{*}{$p$} \\
\hline & & \multicolumn{2}{|c|}{$\mathrm{N}(\%)$ or $\mathrm{M} \pm \mathrm{SD}$} & & \\
\hline \multirow{2}{*}{ Gender } & Male & $10(59)$ & $6(46)$ & \multirow{2}{*}{0.475} & \multirow{2}{*}{0.713} \\
\hline & Female & $7(41)$ & $7(54)$ & & \\
\hline \multirow{4}{*}{ Age (years) } & Less than 50 & $3(18)$ & $3(23)$ & \multirow{3}{*}{0.181} & \multirow{3}{*}{0.913} \\
\hline & $50-69$ & $9(53)$ & $6(46)$ & & \\
\hline & More than 70 & $5(29)$ & $4(31)$ & & \\
\hline & Mean & $61.82 \pm 12.47$ & $61.46 \pm 13.91$ & 0.075 & 0.941 \\
\hline \multirow{2}{*}{ Religion } & Yes & $9(53)$ & $10(77)$ & \multirow{2}{*}{1.824} & \multirow{2}{*}{$0.259^{\dagger}$} \\
\hline & No & $8(47)$ & $3(23)$ & & \\
\hline \multirow{2}{*}{ Marriage } & Married & $12(71)$ & $8(62)$ & \multirow{2}{*}{0.271} & \multirow{2}{*}{$0.705^{\dagger}$} \\
\hline & Divorce, bereavement, separation & $5(29)$ & $5(38)$ & & \\
\hline \multirow{3}{*}{ Education (school) } & $\leq$ Elementary & $6(35)$ & $4(31)$ & \multirow{3}{*}{0.271} & \multirow{3}{*}{0.873} \\
\hline & Middle & $6(35)$ & $4(31)$ & & \\
\hline & $\geq$ High & $5(29)$ & $5(38)$ & & \\
\hline \multirow{2}{*}{ Social security } & Medicaid & $7(41)$ & $5(38)$ & \multirow{2}{*}{0.023} & \multirow{2}{*}{0.880} \\
\hline & Medicare & $10(59)$ & $8(62)$ & & \\
\hline \multirow{2}{*}{ Diagnosis } & Cancer & $11(65)$ & $7(54)$ & \multirow{2}{*}{0.362} & \multirow{2}{*}{0.547} \\
\hline & Other & $6(35)$ & $6(46)$ & & \\
\hline \multirow{2}{*}{ Caregiver } & Yes & $9(53)$ & $10(77)$ & \multirow{2}{*}{1.824} & \multirow{2}{*}{$0.259^{\dagger}$} \\
\hline & No & $8(47)$ & $3(23)$ & & \\
\hline \multirow{2}{*}{ Admission type } & First admission & $13(76)$ & 9 (69) & \multirow{2}{*}{0.197} & \multirow{2}{*}{$0.698^{\dagger}$} \\
\hline & Re-admission & $4(24)$ & $4(31)$ & & \\
\hline \multirow{2}{*}{ Admission reason } & Pain control & $10(59)$ & $7(54)$ & \multirow{2}{*}{0.74} & ( 785 \\
\hline & Symptom control & $7(41)$ & $6(46)$ & & 0.705 \\
\hline
\end{tabular}

\footnotetext{
${ }^{\dagger}=$ Fisher’s exact test; Exp. = Experimental group; Con. = Control group.
}

Table 2. Fatigue between the groups $(\mathrm{N}=23)$.

\begin{tabular}{|c|c|c|c|c|c|c|c|}
\hline \multirow{2}{*}{ Groups } & Pre & Post & \multirow{2}{*}{$\mathrm{t}^{\dagger}$} & \multirow{2}{*}{$p$} & Difference (pre-post) & \multirow{2}{*}{$\mathrm{t}^{\dagger+}$} & \multirow{2}{*}{$p$} \\
\hline & \multicolumn{2}{|c|}{$\mathrm{M}(\mathrm{SD})$} & & & $\mathrm{M}(\mathrm{SD})$ & & \\
\hline Exp. $(n=13)$ & 6.03 (1.99) & $6.09(1.81)$ & -0.227 & 0.824 & $-0.06(1.00)$ & \multirow{2}{*}{-0.813} & \multirow{2}{*}{0.423} \\
\hline Con. $(n=10)$ & $6.15(1.77)$ & $6.31(1.79)$ & -0.565 & 0.586 & $-0.16(0.92)$ & & \\
\hline
\end{tabular}

${ }^{\dagger}=$ paired t-test; ${ }^{\dagger+}=$ independent t-test. 
Table 3. Quantity of sleep for 7 days $^{\dagger}(\mathrm{N}=30)$.

\begin{tabular}{|c|c|c|c|c|c|}
\hline \multirow{2}{*}{ Time(hour) } & \multicolumn{2}{|c|}{ Exp. $(n=17)$} & \multicolumn{3}{|c|}{ Con. $(n=13)$} \\
\hline & \multicolumn{2}{|c|}{$\mathrm{M}(\mathrm{SD})$} & \multicolumn{3}{|c|}{$\mathrm{M}(\mathrm{SD})$} \\
\hline Pretest & \multicolumn{2}{|c|}{$7.70(2.15)$} & \multicolumn{3}{|c|}{7.39 (1.45) } \\
\hline Post 1 day & \multicolumn{2}{|c|}{$6.85(1.52)$} & \multicolumn{3}{|c|}{$6.77(1.88)$} \\
\hline Post 2 days & \multicolumn{2}{|c|}{$6.88(1.40)$} & \multicolumn{3}{|c|}{$7.31(2.18)$} \\
\hline Post 3 days & \multicolumn{2}{|c|}{$7.03(1.55)$} & \multicolumn{3}{|c|}{$7.54(1.28)$} \\
\hline Post 4 days & \multicolumn{2}{|c|}{7.74 (1.17) } & \multicolumn{3}{|c|}{7.50 (1.68) } \\
\hline Post 5 days & \multicolumn{2}{|c|}{7.29 (1.32) } & \multicolumn{3}{|c|}{$6.65(1.31)$} \\
\hline Post 6 days & \multicolumn{2}{|c|}{$7.09(0.75)$} & \multicolumn{3}{|c|}{$6.46(1.05)$} \\
\hline Source & SS & $\mathrm{df}$ & MS & $\mathrm{F}$ & $p$ \\
\hline \multicolumn{6}{|l|}{ Between groups } \\
\hline Groups & 0.996 & 1 & 0.996 & 0.197 & 0.660 \\
\hline Error & 141.242 & 28 & 5.044 & & \\
\hline \multicolumn{6}{|l|}{ Within groups } \\
\hline Time & 20.098 & 4.002 & 5.022 & 1.814 & 0.131 \\
\hline Time x Groups & 9.379 & 4.002 & 2.343 & 0.847 & 0.495 \\
\hline Error & 310.183 & 112.065 & 2.768 & & \\
\hline
\end{tabular}

${ }^{\dagger}=$ Repeated Measures ANOVA.

Table 4. Quality of sleep between the groups $(\mathrm{N}=30)$.

\begin{tabular}{|c|c|c|c|c|c|c|c|}
\hline \multirow{2}{*}{ Group } & Pre te & st test & \multirow{2}{*}{$\mathrm{t}^{\dagger}$} & \multirow{2}{*}{$p$} & Difference (pre-post) & \multirow{2}{*}{$\mathrm{t}^{\dagger \dagger}$} & \multirow{2}{*}{$p$} \\
\hline & \multicolumn{2}{|c|}{$\mathrm{M}(\mathrm{SD})$} & & & $\mathrm{M}(\mathrm{SD})$ & & \\
\hline Exp. $(n=17)$ & $4.65(1.73)$ & $4.87(1.55)$ & -0.914 & 0.375 & $-0.22(0.10)$ & \multirow{2}{*}{0.481} & \multirow{2}{*}{0.634} \\
\hline Con. $(n=13)$ & $4.46(1.51)$ & $4.61(1.23)$ & -0.407 & 0.691 & $-0.15(1.36)$ & & \\
\hline
\end{tabular}

${ }^{\dagger}=$ paired t-test; ${ }^{\dagger \dagger}=$ independent t-test.

mental group was initially as high as 7.70 and decreased to 7.09 in 6 days. The quantity of sleep level in the comparison group was initially as high as 7.39 and decreased to 6.46 in 6 days. Repeated measures ANOVA showed that there was no significant difference in the quantity of sleep level between the groups. The quality of sleep level in both groups was presented in Table 4. The quality of sleep in the experimental group was initially 4.65 and increased to 4.87. The quality of sleep level in the comparison group was initially 4.46 and also increased to 4.61. But, there was no significant difference in the quality of sleep between the groups.

\section{Discussion}

The purpose of this study was to compare the effects of aroma hand massage with only hand massage on fatigue and sleep. The massage for both groups was provided at $9 \sim 10 \mathrm{pm}$ right before bed time for a total of 10 minutes to the clients' both hands for 5 consequent days.

The findings of this study showed even though there was no significant difference in the effects of aroma hand massage with only hand massage on fatigue, the increase in the fatigue level in the aroma hand massage group was lower than the only hand massage group. The findings of the current study were partially consistent with the study of Wilcock and colleagues (2004) [33]. Wilcock and colleagues (2004) [33] compared the effect of aromatherapy with day care alone on fatigue in cancer patients at a palliative care day centre and reported no significant difference between the 2 groups. They used a blend of $1 \%$ lavender and chamomile in sweet almond carrier oil for 30 minutes weekly for a total of 4 sessions. The 2 studies showed no significant difference in fatigue between the 2 groups when provided to hospice clients. When considered hospice clients experience serious fatigue as time goes by, the slow increase in fatigue level would be meaningful to hospice clients.

On the other hand, a few studies reported that aromatherapy using lavender improved fatigue, as compared to 
the control group when offered to patients with pain or hemodialysis [19] [20]. In Kang and Kim's study (2008) [19], aromatherapy was provided to improve fatigue for hemodialysis patients. The aroma hand massage was provided for 5 minutes for a total of 12 times ( 3 times/week for 4 weeks). The oils were a mixture of lavender, chamomile and geranium oil in the ratio of 4:4:2. The mixture was diluted to $3 \%$ with $100 \mathrm{ml}$ sweet almond carrier oil. The reviewed study showed a lower fatigue level in the aroma hand massage group than in the comparison group. In addition, Kim and Kim (2009) [20] reported a lower fatigue level in the aroma hand massage group than in the comparison group (without essential oil). The treatment was performed for 5 to 10 minutes for a total of 14 sessions (2 times a day for 2 weeks) and lavender, chamomile and ginger oil were used. Based on this comparison, while the aromatherapy improved the fatigue in patients with hemodialysis and pain [19] [20], it did not in the hospice patients. While previous studies reported a significant improvement on fatigue by providing the aromatherapy for 5 to 10 minutes over 12 times for over 2 weeks, the current study offered treatment for only 5 times in total because of the hospice patients' health condition. It is assumed that 5 sessions of aroma therapy were not enough to produce a significant effect on fatigue for the hospice patients. It may be worthwhile to investigate the effect of aroma hand massage given for more than 5 sessions in further studies if the health condition of hospice patients is sufficient and patients are selected on basis of their health condition.

Fatigue is caused by different factors such as pain, depression, low quality of life and functional limitations [34], but those factors were not initially assessed and controlled in this study because the hospice clients complained of being tired by measurements with several instruments. Thus, these factors need to be measured in further studies if possible. We measured the fatigue level only once after the massage therapy had been started, at the post-test when the massage was completed. It is recommended to measure the fatigue level more than once to investigate the continuous effect of massage on fatigue in hospice clients during a study.

The findings of the current study showed no difference in sleeping between the both groups. They were consistent with previous studies [32]. Soden and colleagues (2004) [32] compared the effect of aroma massage therapy with massage only on sleeping in hospice clients. Lavender was chosen as the essential oil and mixed in sweet almond oil to a dilution of 1\%. Each intervention was received for 30 minutes in the morning, weekly for 4 weeks. Soden's study (2004) [32] showed no significant difference in sleeping between the 2 groups and the findings were consistent with the current study. On the other hand, Lee and Kim's study (2011) [35] reported significant differences in sleep satisfaction and sleeping hours between the aroma hand massage group and massage group. In the study of Lee and Kim (2011) [35], 1\% lavender essential oil with 50 ml sweet almond oil was used once per day for 3 days right before going to sleep. For the hand massage group, a massage with sweet almond oil without any essential oil was applied in the same way. All 3 studies compared the effects of aroma hand massage with hand massage on sleeping of hospice clients or cancer clients and used the same lavender essential oil with $1 \%$ dilution even though the timing and duration of intervention were different. For consistent findings, further studies would be needed with larger sample size and longer duration of treatment.

We used lavender and bergamot essential oils because they were reported to help clients relax in previous studies [15] [21]. One study subject expressed displeasure with the smell of the oil in the early days of this study and wanted to drop from the study. Also, a few subjects in the experimental group wanted sometimes only massage without aroma oil to be applied a couple of times, but they did not want to drop from the group. Based on the findings, even though lavender and bergamot oils have been reported as 2 of the best oils for inducing relaxation, the client's preferences for the type of oil needs to be taken into consideration. In addition, comparisons of the effects of different types of oils need to be conducted to determine the best oil for alleviating fatigue and improving sleep in hospice clients in further studies.

In this study, the essential oil was blended to $1 \%$ because essential oils diluted to $1 \%$ were used in previous studies on cancer patients [31] [32]. However, many subjects in this study mentioned that they could not smell the oil well and they could not tell if there was any difference between the massage oil containing the essential oil and the massage oil that did not contain the essential oil. In the present study, most of subjects were hospice clients with cancer and they differed in their ability to smell the essential oil because of their health status, so there is a need to assess the clients' individual ability to smell in order to assess the maximum effect that essential oils have on subjects including their effect on the olfactory organ. It may be useful to compare the effect on fatigue and sleep of oils that have been blended with other oils at different proportions in hospice patients. In addition, it is needed to test blending the essential oil to $1 \%$ for hospice clients is appropriate or not.

The findings of this study are too limited to draw definite conclusions because the study was conducted on only 30 subjects staying at 1 local hospital. In addition, the measurement of fatigue was conducted only once af- 
ter the interventions were initiated at the completion of the interventions. Therefore, it was difficult to investigate consistent effects of aroma massage on fatigue, because this requires multiple measurements at different moments. Thus, investigating the consistent effects of aroma massage with different types of oil on hospice clients in different settings is recommended for further studies.

\section{Conclusion}

We compared the effect on fatigue and sleep of aroma hand massage vs. only hand massage without aroma oil in hospice patients. The findings of this study showed that there were no significant differences on fatigue, quantity of sleep and quality of sleep between both groups. Because the current study provided only 5 times of aroma hand massage and showed no effects, the authors suggested further studies with more than 5 sessions to investigate the significant effects of the interventions if the health condition of hospice patients was adequate. In this study, some of hospice patients seriously mentioned that they could not even smell the aroma oil or they did not prefer the certain smell of aroma oil even though lavender and bergamot oils were reportedly the 2 best oils for relaxation induction. Therefore, it was recommended to consider the client's preferences for the type of oil prior to the initiation of any aroma therapy in further studies.

\section{References}

[1] Hutcheson, A. (2011) Hospice Care in the United States. Primary Care: Clinics in Office Practice, 38, 173-182. http://dx.doi.org/10.1016/j.pop.2011.03.002

[2] 2010 Elderly's Statistics: Korean Statistical Information Service. http://kostat.go.kr/portal/korea/kor_nw/2/1/index.board?bmode=read\&aSeq=180000

[3] Kang, J.A., Koh, S.J., Kim, D.G., Kim, M.J., Kim, S.J., Kim, O.K., et al. (2012) Introduction of Hospice and Palliative Care for Palliative Care Team. Rev. Ed., Ministry of Health \& Welfare, National Cancer Center, Seoul \& Gyeonggido.

[4] Javier, N.S. and Montagnini, M.L. (2011) Rehabilitation of the Hospice and Palliative Care Patient. Journal of Palliative Medicine, 14, 638-648. http://dx.doi.org/10.1089/jpm.2010.0125

[5] Radbruch, L., Strasser, F., Elsner, F., Goncalves, J.F., Loge, J., Kaasa, S., et al. (2008) Fatigue in Palliative Care Patients—An EAPC Approach. Palliative Medicine, 22, 13-32. http://dx.doi.org/10.1177/0269216307085183

[6] Byun, H.S., Kim, G.D., Chung, B.Y. and Kim, K.H. (2010) Fatigue and Quality of Life of Korean Cancer Inpatients. The Korean Journal of Hospice and Palliative Care, 13, 98-108.

[7] Jung, E.J., Park, M.I. and Jung, Y. (2004) Factors Related to Fatigue in Cancer Patients Receiving Chemotherapy. The Korean Journal of Hospice and Palliative Care, 7, 179-188.

[8] Kim, Y.H. and Han, J.S. (2011) Factors Related to the Quality of Sleep in the Elderly Women. Journal of the Korea Academia-Industrial Cooperation Society, 12, 4467-4474. http://dx.doi.org/10.5762/KAIS.2011.12.10.4467

[9] Sok, S.H. and Choi, J.H. (2010) Factors Influencing Sleep of Elderly Women. Journal of Korean Academy of Nursing, 40, 119-126. http://dx.doi.org/10.4040/jkan.2010.40.1.119

[10] Lee, H.M., Ryu, S.A. and Kim, E.A. (2009) Factors Influencing Sleep Disorders in Patients on Hemodialysis. Journal of Korean Academy of Fundamentals of Nursing, 16, 190-199.

[11] Chang, S.Y. (2008) Effects of Aroma Hand Massage on Pain, State Anxiety and Depression in Hospice Patients with Terminal Cancer. Journal of Korean Academy of Nursing, 38, 493-502. http://dx.doi.org/10.4040/jkan.2008.38.4.493

[12] Buss, T., de Walden-Galuszko, K., Modlinska, A., Osowicka, M., Lichodziejewska-Niemierko, M. and Janiszewska, J. (2010) Kinesitherapy Alleviates Fatigue in Terminal Hospice Cancer Patients-An Experimental, Controlled Study. Supportive Care in Cancer: Official Journal of the Multinational Association of Supportive Care in Cancer, 18, 743749. http://dx.doi.org/10.1007/s00520-009-0709-0

[13] Choi, Y.K. (2010) The Effect of Music and Progressive Muscle Relaxation on Anxiety, Fatigue, and Quality of Life in Family Caregivers of Hospice Patients. Journal of music therapy, 47, 53-69. http://dx.doi.org/10.1093/jmt/47.1.53

[14] Styles, J. (1997) The Use of Aromatherapy in Hospitalized Children with HIV. Complementary Therapies in Nursing, 3, 16-20. http://dx.doi.org/10.1016/S1353-6117(97)80029-7

[15] Buckley, J. (2002) Massage and Aromatherapy Massage: Nursing Art and Science. International Journal of Palliative Nursing, 8, 276-280. http://dx.doi.org/10.12968/ijpn.2002.8.6.10497

[16] Halcon, L.L. and Buckle, J. (2006) Aromatherapy. In: Snyder, M. and Lindquist, R., Eds., Complementary/Alternative therapies in Nursing, 5th Edition, Springer Publishing Company, New York, 323-344.

[17] Kolcaba, K., Dowd, T., Steiner, R. and Mitzel, A. (2004) Efficacy of Hand Massage for Enhancing the Comfort of 
Hospice Patients. Journal of Hospice and Palliative Nursing, 6, 91-102. http://dx.doi.org/10.1097/00129191-200404000-00012

[18] Lin, P.W., Chan, W.C., Ng, B.F. and Lam, L.C. (2007) Efficacy of Aromatherapy (Lavandula angustifolia) as an Intervention for Agitated Behaviours in Chinese Older Persons with Dementia: A Cross-Over Randomized Trial. International Journal of Geriatric Psychiatry, 22, 405-410. http://dx.doi.org/10.1002/gps.1688

[19] Kang, S.J. and Kim, N.Y. (2008) The Effects of Aroma Hand Massage on Pruritus, Fatigue and Stress of Hemodialysis Patients. The Journal of Korean Academic Society of Adult Nursing, 20, 883-894.

[20] Kim, I.J. and Kim, E.K. (2009) Effects of Aroma Massage on Pain, Activities of Daily Living and Fatigue in Patients with Knee Osteoarthritis. Journal of Muscle and Joint Health, 16, 145-153.

[21] Lee, J.E., Lee, Y.W. and Kim, H.S. (2011) Effects of Aroma Hand Massage on the Stress Response and Sleep of Elderly Inpatients. Journal of Korean Academy of Fundamentals of Nursing, 18, 480-487.

[22] Kim, M.H. and Sung, K.W. (2006) The Effects of Aroma Foot Massage on the Anxiety, Pain and Sleep Satisfaction during Colonoscopy under Conscious Sedation. Journal of Korean Academy of Community Health Nursing, 17, 91101.

[23] Jung, H.N. and Choi, H.J. (2012) Effects of Lavandula angustifolia Aroma on Electroencephalograms in Female Adults with Sleep Disorders. Journal of Life Science, 22, 192-199. http://dx.doi.org/10.5352/JLS.2012.22.2.192

[24] Faul, F., Erdfelder, E., Buchner, A. and Lang, A.G. (2009) Statistical Power Analyses Using G*Power 3.1: Tests for Correlation and Regression Analyses. Behavior Research Methods, 41, 1149-1160. http://dx.doi.org/10.3758/BRM.41.4.1149

[25] Piper, B.F., Dibble, S.L., Dodd, M.J., Weiss, M.C., Slaughter, R.E. and Paul, S.M. (1998) The Revised Piper Fatigue Scale: Psychometric Evaluation in Women with Breast Cancer. Oncology Nursing Forum, 25, 677-684.

[26] Sohn, S.K. (2002) Relationship between Fatigue and Sleep Quality in Patients with Cancer. Journal of Korean Academic Society of Adult Nursing, 14, 378-389.

[27] Snyder-Halpern, R. and Verran, J.A. (1987) Instrumentation to Describe Subjective Sleep Characteristics in Healthy Subjects. Research in Nursing \& Health, 10, 155-163. http://dx.doi.org/10.1002/nur.4770100307

[28] Smith, M.C., Kemp, J., Hemphill, L. and Vojir, C.P. (2002) Outcomes of Therapeutic Massage for Hospitalized Cancer Patients. Journal of Nursing Scholarship, 34, 257-262. http://dx.doi.org/10.1111/j.1547-5069.2002.00257.x

[29] Kang, J.E. and Kim, K.S. (1994) The Effect of Preparatory Audiovisual Information with Videotape Influencing on Sleep and Anxiety of Abdominal Surgical Patients. Journal of Korean Academy of Fundamentals of Nursing, 1, 19-36.

[30] Kim, S.M., Kim, G.R., Kim, R., Kim, B.I. and Kim, S.O. (2013) Theory and Practice of Aromatherapy. Korea Aromatherapy Association, Jungmunkag.

[31] Kohara, H., Miyauchi, T., Suehiro, Y., Ueoka, H., Takeyama, H. and Morita, T. (2004) Combined Modality Treatment of Aromatherapy, Footsoak, and Reflexology Relieves Fatigue in Patients with Cancer. Journal of Palliative Medicine, 7, 791-796. http://dx.doi.org/10.1089/jpm.2004.7.791

[32] Soden, K., Vincent, K., Craske, S., Lucas, C. and Ashley, S. (2004) A Randomized Controlled Trial of Aromatherapy Massage in a Hospice Setting. Palliative Medicine, 18, 87-92. http://dx.doi.org/10.1191/0269216304pm874oa

[33] Wilcock, A., Manderson, C., Weller, R., Walker, G., Carr, D., Carey, A.M., et al. (2004) Does Aromatherapy Massage Benefit Patients with Cancer Attending a Specialist Palliative Care Day Centre? Palliative Medicine, 18, $287-290$. http://dx.doi.org/10.1191/0269216304pm895oa

[34] Jakobsson, U. (2006) A Literature Review on Fatigue among Older People in Pain: Prevalence and Predictors. International Journal of Older People Nursing, 1, 11-16. http://dx.doi.org/10.1111/j.1748-3743.2006.00004.x

[35] Lee, E. and Kim, K.S. (2011) The Effects of Aroma Hand Massage on Anxiety and Sleep in Cancer Patients during Hospitalization. Perspectives in Nursing Science, 8, 42-53. 


\section{Submit or recommend next manuscript to SCIRP and we will provide best service for you:}

Accepting pre-submission inquiries through Email, Facebook, Linkedin, Twitter, etc A wide selection of journals (inclusive of 9 subjects, more than 200 journals)

Providing a 24-hour high-quality service

User-friendly online submission system

Fair and swift peer-review system

Efficient typesetting and proofreading procedure

Display of the result of downloads and visits, as well as the number of cited articles

Maximum dissemination of your research work

Submit your manuscript at: http://papersubmission.scirp.org/ 